\title{
Differential effects of interleukin-1 alpha and beta on interleukin-6 and chemokine synthesis in neurones
}

\author{
Niki Tsakiri, Ian Kimber, Nancy J. Rothwell, ${ }^{*}$ and Emmanuel Pinteaux \\ Faculty of Life Sciences, Michael Smith Building, University of Manchester, Oxford Road, Manchester, M13 9PT, United Kingdom
}

Received 29 January 2008; accepted 26 February 2008

Available online 18 March 2008

Interleukin (IL)-1 is a key mediator of neuroinflammation via actions of two agonists IL-1 $\alpha$ and $\beta$ that bind to the IL-1 type I receptor (IL$1 R I)$, and are thought to trigger identical responses. However, evidence suggests that IL-1 $\alpha$ and $\beta$ may have differential actions in the central nervous system (CNS). The objective of this study was to test the hypothesis that $\mathrm{IL}-1 \alpha$ and $\beta$ differentially regulate the expression of IL-6 and chemokines KC, IP-10 and MCP-1 in primary neurones. Here we demonstrate that, whilst IL-1 $\beta$ induced significant synthesis of IL-6 in neurones, IL-1 $\alpha$ had no effect. In contrast, IL-1 $\alpha$ and $\boldsymbol{\beta}$ induced strong synthesis and constitutive release of chemokines KC, IP-10 and MCP-1 from neurones, and these responses were IL1RI-dependent. Whilst IL-1 $\beta$-induced IL-6 synthesis was dependent on the nSMase/Src kinase signalling cascade, specific inhibitors of nSMase (3-OMS) and Src kinase (PP2) failed to inhibit IL-1 $\alpha$ - and IL-1 $\beta$-induced chemokines synthesis, suggesting the existence of alternative signalling pathway(s) in neurones.

(C) 2008 Elsevier Inc. All rights reserved.

\section{Introduction}

Interleukin (IL)-1 is a prototypic proinflammatory cytokine involved in the immune response to infection and injury, and is a primary mediator of inflammatory responses to acute and chronic central nervous system (CNS) disorders (Allan et al., 2005; Rothwell, 2003). IL-1 also contributes to the regulation of physiological functions such as sleep, memory and long-term potentiation (LTP), as well as host defence responses such as fever and sickness behaviour (Bilbo et al., 2005; Dantzer et al., 1998; Ross et al., 2003; Schneider et al., 1998).

IL- $1 \alpha$ and $\beta$ are the two established functional agonists of the IL-1 family that bind to a specific, membrane-associated IL-1 type I receptor (IL-1RI) (Sims et al., 1988), which associates with the IL-1 receptor accessory protein (IL-1RAcP) (Wesche et al., 1997) to activate downstream signalling cascades. In the CNS, IL- $1 \alpha$ and $\beta$ trigger in glial cells the activation of mitogen-activated protein kinases (MAPKs) and nuclear factor-kappa B (NFKB), leading to the

\footnotetext{
* Corresponding author. Fax: +44 1612755948.

E-mail address: nancy.rothwell@manchester.ac.uk (N.J. Rothwell).

Available online on ScienceDirect (www.sciencedirect.com).
}

production of key inflammatory mediators such as IL-6, prostaglandins E2 and chemokines (Kim et al., 2004; Parker et al., 2002), and all these actions are blocked by the naturally occurring IL-1 receptor antagonist (IL-1RA). We have recently reported that IL-1 $\beta$ also induces in neurones the synthesis of IL- 6 but via distinct pathways including neutral sphingomyelinase (nSMase)/ceramide and Src kinase (Tsakiri et al., 2008a), but whether this signalling pathway is activated by IL-1 $\alpha$ in neuronal cells to produce IL- 6 is unknown.

IL- $1 \alpha$ and $\beta$ are believed to induce identical cellular responses, but there have been reports of differences in the activity of these two ligands both peripherally and centrally in rodents. For instance, $\mathrm{T}$ cell-dependent antibody production is mediated by IL-1 $\beta$, but not IL-1 $\alpha$ (Nakae et al., 2001) and the ligands have differential effects on some aspects of cutaneous immune function (Cumberbatch et al., 2002) and tumour development (Song et al., 2003). In the rat CNS, IL-1 $\beta$ is much more effective at inducing fever than IL-1 $\alpha$ when injected intracerebroventrically (icv) (Anforth et al., 1998). Furthermore IL-1 $\beta$, but not IL-1 $\alpha$, induces nerve growth factor (NGF) release from astrocytes (Juric and Carman-Krzan, 2001) and, despite inducing similar levels of activation of MAPKs/NFKB in glia, IL- $1 \beta$ is more potent that IL$1 \alpha$ at inducing IL-6 release from these cells (Andre et al., 2005). The effect of IL- $1 \alpha$ on neuronal IL- 6 production is not known and the aim of this study was to compare the effects of IL- $1 \alpha$ and IL-1 $\beta$ on expression of IL- 6 and other inflammatory mediators identified by cDNA microarray analysis, such as chemokines KC (CXCL1), IP-10 (CXCL10) and MCP-1 (CCL2) in primary neurones. We show here that, unlike IL- $1 \beta$, IL- $1 \alpha$ fails to induce IL- 6 synthesis in neurones, and demonstrate for the first time that both ligands are potent inducers of chemokines synthesis and release, via an nSMase/Src kinase-independent signalling mechanism.

\section{Results}

$I L-1 \beta$, but not $I L-1 \alpha$, induces $I L-6 m R N A$ and protein synthesis in primary neurones

IL-1 $\beta(0.003$ to $3 \mathrm{U} / \mathrm{ml})$ dose-dependently induced significant IL-6 gene expression after $4 \mathrm{~h}$ in primary neurones, with maximum induced expression (57-fold) obtained with the dose of $0.3 \mathrm{U} / \mathrm{ml}$ 
(Fig. 1A). In contrast, IL-1 $\alpha$ failed to induce IL-6 mRNA expression and all concentrations tested were found to be less potent in inducing IL- 6 gene expression than the equivalent concentrations of IL-1 $\beta$. A statistically significant difference was observed between IL- $1 \alpha$ and IL- $1 \beta$-induced IL- 6 gene expression at a dose of $0.3 \mathrm{U} / \mathrm{ml}$. IL-1 $\beta$ $(0.03$ to $30 \mathrm{U} / \mathrm{ml})$ also induced significant synthesis of IL-6 protein in the cells, with maximum synthesis detected in response to the concentration of $0.3 \mathrm{U} / \mathrm{ml}$, but IL- $1 \alpha$ again had no effect on IL-6 protein expression in the cell supernatant or lysates of treated cells (Fig. 1B). IL-1 $\alpha$ induced only a slight, but non-significant increase in IL-6 protein levels in the cell lysates at all concentrations tested, and no significant release of the protein in the culture medium. IL-1 $\beta$ produced significantly higher levels of IL- 6 compared to IL- $1 \alpha$ at the concentration of $0.03-3 \mathrm{U} / \mathrm{ml}$.

$I L-1 \alpha$ and $I L-1 \beta$ induce synthesis of the chemokines $K C, I P-10$ and $M C P-1$ in primary neurones

To identify the profile of changes in gene expression induced by IL-1 in neurones, we used cDNA microarray-based gene expression

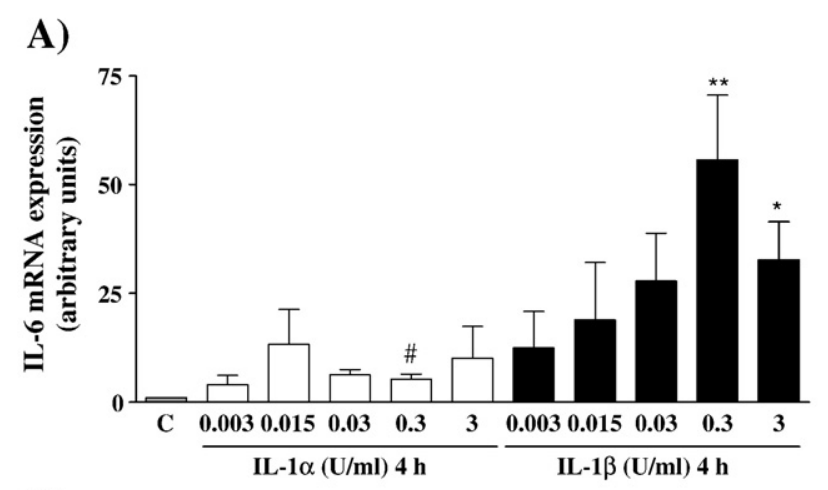

B)

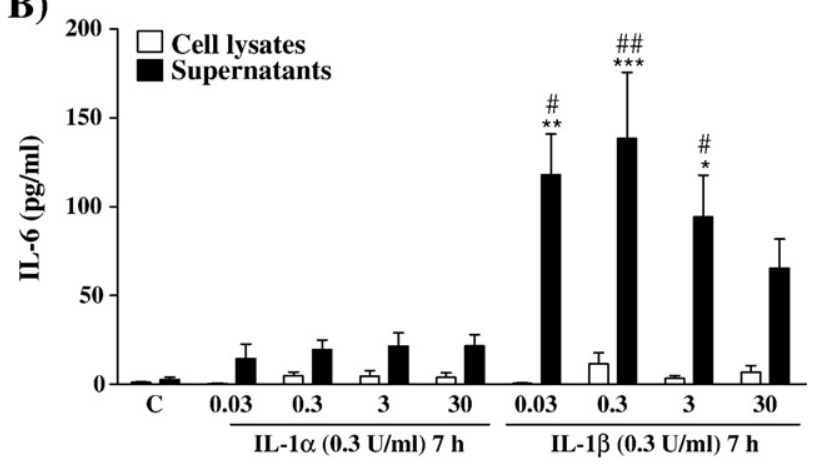

Fig. 1. IL-6 mRNA and protein expression in IL- $1 \alpha-$ and IL-1 $\beta$-treated neuronal cell cultures. Primary cortical neuronal cell cultures were treated with vehicle (C), IL-1 $\alpha$ or IL-1 $\beta$ ( 0.003 to $30 \mathrm{U} / \mathrm{ml})$ for 4 or $7 \mathrm{~h}$. (A) cDNA from the cultures was prepared and used for SYBR-green real-time PCR using specific primers for IL- 6 and $\beta$-actin. Two melting curves for primer binding were constructed to ensure that cDNA amplification was due to a single PCR product. Expression of the two genes was determined by the standard curves, and IL-6 expression was normalised to $\beta$-actin expression levels. Data are presented as the mean $\pm \mathrm{SD}$ of three independent experiments ${ }^{*} p<0.05$, ${ }^{* *} p<0.001$, C vs. IL- $1 \beta,{ }^{*} p<0.05$, IL- $1 \alpha$ vs. IL- $1 \beta$, one-way ANOVA with Bonferroni's multiple comparison post-hoc test. (B) Cell lysates and supernatants were collected and assayed with a mouse-specific IL-6 ELISA. Data are presented as the mean $\pm \mathrm{SD}$ of seven independent experiments ${ }^{*} p<0.05$, ${ }^{* *} p<0.01,{ }^{* * *} p<0.001, \mathrm{C}$ vs. IL-1 $\beta,{ }^{*} p<0.05,{ }^{\# \#} p<0.001$, IL-1 $\alpha$ vs. IL-1 $\beta$, one-way ANOVA with Bonferroni's multiple comparison post-hoc test. profiling in neuronal cultures treated with IL-1 $\beta$. The genes that showed significant changes in their expression were consistently upregulated by IL- $1 \beta$ across all three independent experiments, and were all identified as inflammatory mediators (Fig. 2); In addition to IL-6, marked induction of gene expression was seen for chemokines e.g the murine homologue of GRO $\alpha$ (KC, also known as CXCL1) (62.8-fold), interferon- $\gamma$ inducible protein $10 \mathrm{kDa}$ (IP-10, also known as CXCL10) (13.2-fold), the murine homologue of MCP-1 (MCP-1, also known as CCL2) (14.4-fold), as well as macrophage colony stimulating factor (M-CSF) (4.0-fold) and the intercellular adhesion molecule 1 (ICAM-1) (1.9-fold). All these effects were reversed by co-incubation with IL-1RA.

The expression profile of KC, IP-10 and MCP-1 proteins was studied in cortical neurones treated with the same biologically active dose of IL- $1 \alpha$ or IL- $1 \beta(0.3 \mathrm{U} / \mathrm{ml})$ for 1 to $24 \mathrm{~h}$. Significant up-regulation of $\mathrm{KC}$, IP-10 and MCP-1 protein levels were detected in response to IL- $1 \alpha$ or IL- $1 \beta$ compared to vehicle $(\mathrm{C})$, as early as $2 \mathrm{~h}$ for KC and MCP-1, and $3 \mathrm{~h}$ for IP-10 (Fig. 3), and the effects were similar for both forms of IL-1. The dramatic increase in the levels of all three chemokines KC, IP-10 and MCP-1 was observed in cell lysates and in culture supernatants, suggesting that, unlike IL-6, the proteins were released constitutively in response to IL-1. In addition to increases in the levels of the chemokines detected in the culture supernatants, a significant increase in MCP-1 levels was detected in the cell lysates (Fig. 3C). IL- $1 \alpha$ and IL-1 $\beta$ produced similar up-regulation in the protein levels of the chemokines, and a similar time course of release. Upregulation of $\mathrm{KC}$, IP-10 and MCP- 1 by IL- $1 \alpha$ or IL- $1 \beta$ was reversed by IL-1RA, whilst IL-1RA alone had no significant effect on the regulation of chemokines protein levels (not shown).

$I L-1 \alpha$ - and $I L-1 \beta$-induced release of $K C, I P-10$ and $M C P-1$ is independent of nSMase and Src kinase signalling pathway in primary neurones

We have demonstrated previously that IL-1 $\beta$-induced IL-6 synthesis in neurones is dependent on the activation of the neuronal-specific nSMase/Src kinase signalling pathway (Tsakiri et al., 2008a). We therefore determined whether the same pathway is involved in the synthesis of chemokines induced by IL-1. Coincubation of cultures with IL- $1 \alpha$ or IL-1 $\beta$ and the Src kinase inhibitor PP2 $(10 \mu \mathrm{M})$ or nSMase inhibitor 3-OMS $(25 \mu \mathrm{M})$, induced a slight, but non-significant reduction of KC and IP-10 in culture supernatants, whereas PP2 or 3-OMS had no effect on the intracellular levels of KC and IP-10 (Fig. 4A/B). PP2 or 3-OMS had no effect on IL-1-induced MCP-1 synthesis (Fig. 4C).

\section{Discussion}

In this study we demonstrate that unlike having a differentially effect on IL- 6 synthesis, IL- $1 \alpha$ and $\beta$ are potent inducers of chemokines synthesis and release, via an nSMase/Src kinaseindependent signalling mechanism, suggesting the existence an alternative signalling pathway in neurones.

Proinflammatory actions of IL- $1 \alpha$ and $\beta$ are mediated in the CNS primarily by glial cells that produce various inflammatory mediators including IL-6 and chemokines (Kim et al., 2004; Parker et al., 2002). IL-1 $\beta$ also induces IL-6 synthesis in neurones (Tsakiri et al., $2008 \mathrm{a}, \mathrm{b})$, but the effect of IL-1 $\alpha$ was unknown. In the present study, we confirm that IL- $1 \beta$ induces significant synthesis of IL- 6 in neurones, and demonstrate that the same biologically active doses of 


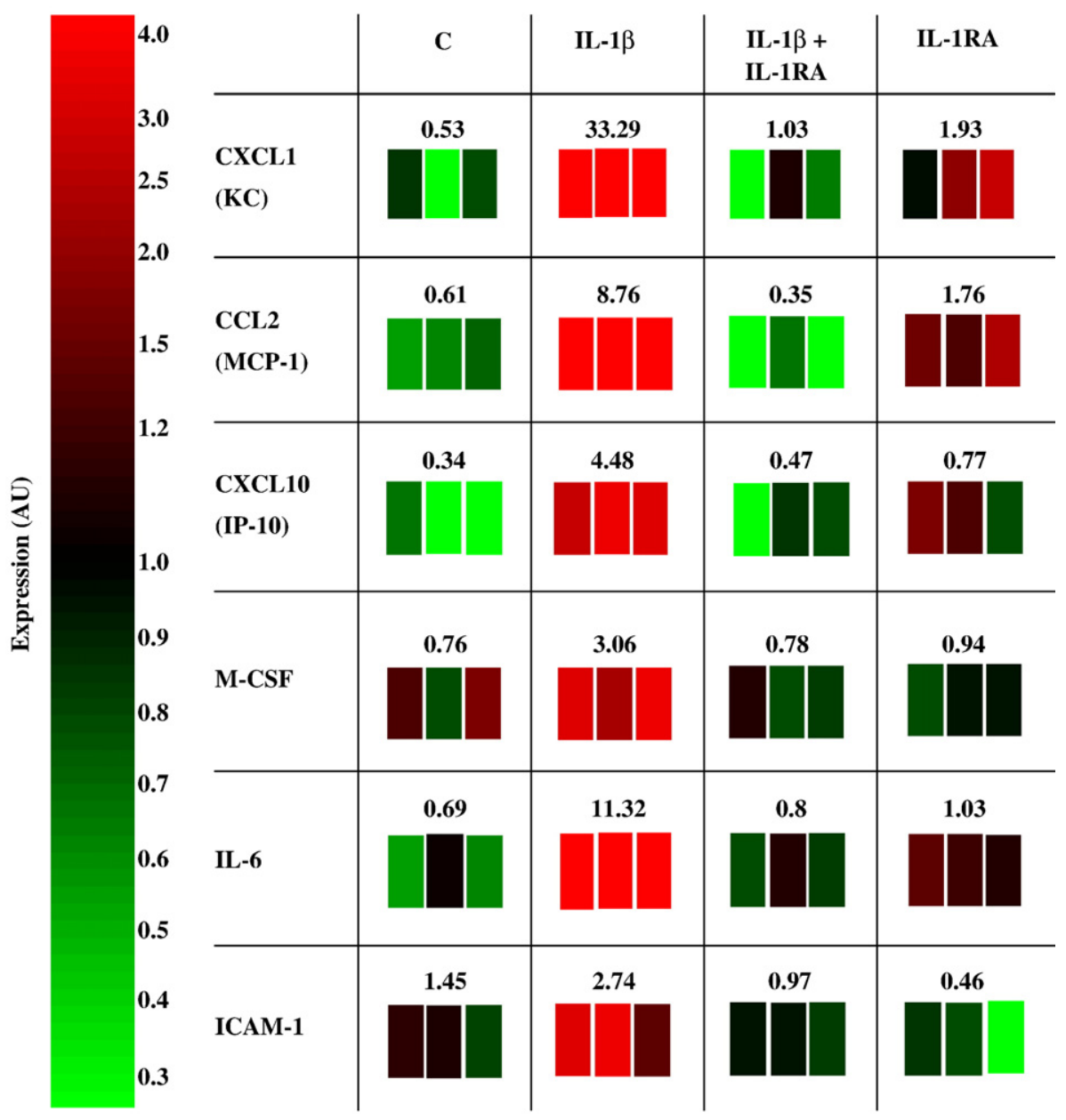

Fig. 2. Analysis of GeneChip ${ }^{\circledR}$ microarray-based gene expression profiling from IL-1 $\beta$-treated neurones. Genes whose expression changed significantly (over 2.5 arbitrary units (AU) between the different treatments were selected and identified as key inflammatory mediators (KC, MCP-1 and IP-10, the macrophage colony stimulating factor (M-CSF), and intercellular adhesion molecule 1 (ICAM-1)). These genes were upregulated by IL-1 $\beta$, and this effect was reversed by co-incubation with IL-1RA. The arithmetic values of the table represent the mean expression (AU) of each gene from the three experiments, and the coloured boxed underneath represents the expression intensity of each gene in each individual experiment.

IL- $1 \alpha$ fail to induce IL- 6 synthesis, providing further evidence of differential actions of these two ligands in the CNS. Indeed we have demonstrated previously that IL- $1 \beta$ is more potent that IL- $1 \alpha$ at inducing fever and IL-6 production from glia (Anforth et al., 1998; Andre et al., 2005). Furthermore we have investigated the effect of these two ligands on the expression of other inflammatory mediators in neuronal cells, and we demonstrate for the first time that IL- $1 \alpha$ and IL-1 $\beta$ produce a strong and rapid synthesis of three major chemokines KC, IP-10 and MCP-1 in primary neurones (Figs. 2 and 3). The similar effect of both IL-1 ligands on chemokine synthesis demonstrates that the preparations of recombinant IL-1 used in our study are equally bioactive. KC, IP-10 and MCP-1 are known to be highly expressed after CNS injury, and are key mediators of inflammation, via actions on glia and neurones, which express the functional receptors CXCR2 (for KC), CCR2 (for MCP-1), and CXCR3 (for IP-10) (Barbero et al., 2002; Cho and Miller, 2002). Our data are the first to demonstrate that IL-1 can directly activate neuronal cells to produce chemokines, which could be an important mechanism for the recruitment of microglia to the site of neuronal injury.

Importantly, both IL-1 ligands appeared to be equally potent in the regulation of expression of these chemokines, in the time-course and magnitude of expression, indicating that the marked difference in their effects on IL-6 could not be ascribed to differences in biological activity. In addition, these chemokines appeared to be released from the cells into the culture supernatants, in contrast to IL6 , which was stored intracellularly and needs a secondary stimulus for its release (Tsakiri et al., 2008b). Here again, both IL-1 ligands had similar potency on the release of these chemokines. The fact that IL- $1 \alpha$ and IL- $1 \beta$ have identical effects on KC, IP-10 and MCP-1 expression, but differentially induce IL-6, cannot be attributed to signalling through another receptor since the effects of both IL-1 ligands were abolished by IL-1RA, which blocks actions through IL1R1. Moreover both IL-1 $\alpha$ and IL- $1 \beta$ have similar binding affinities for IL-1R1 (Dower et al., 1986). The differential effects of IL- $1 \alpha$ and IL- $1 \beta$ could be explained by the recruitment of additional/alternative receptor accessory protein or adaptor proteins to the receptor complex, which could trigger differential binding affinity for one of the ligands, activation of other intracellular signalling pathways and/ or more prolonged activation of the existing pathway.

$\mathrm{IL}-1 \beta$ is known to induce in neurones the activation of Src kinase through nSMase, leading to an increase in intracellular $\mathrm{Ca}^{2+}$ concentration from NMDA receptors that controls IL-6 synthesis (Tsakiri et 


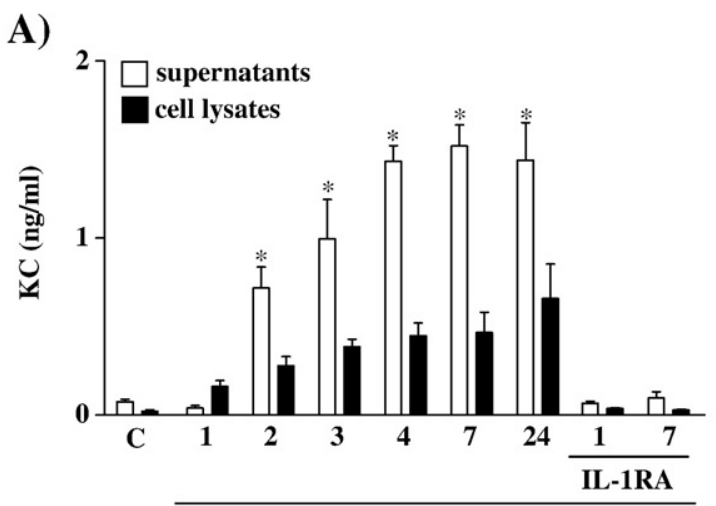

IL-1 $\alpha(0.3 \mathrm{U} / \mathrm{ml}) \mathrm{h}$

B)

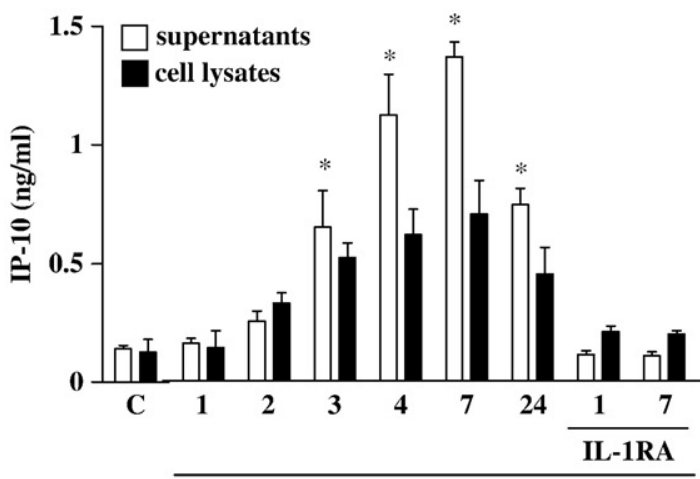

IL-1 $\alpha(0.3 \mathrm{U} / \mathrm{ml})$ h

C)

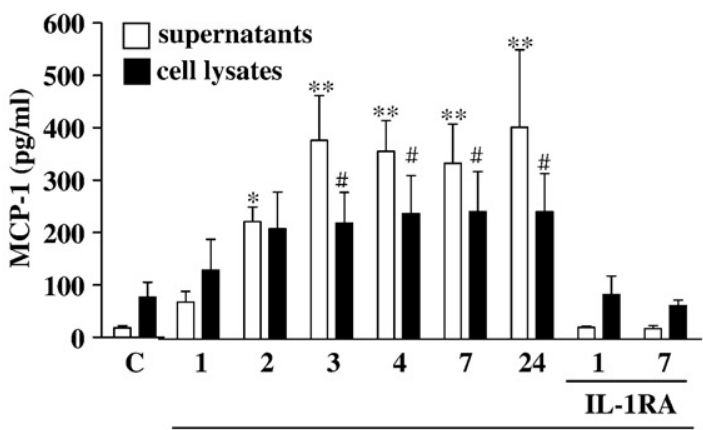

IL-1 $\alpha(0.3 \mathrm{U} / \mathrm{ml}) \mathrm{h}$

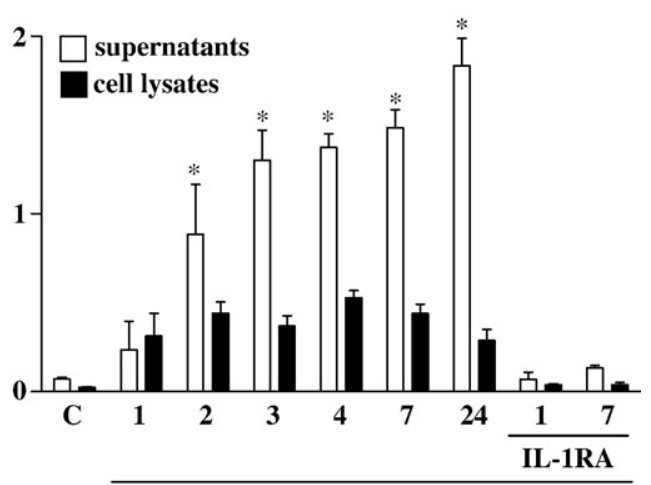

IL-1 $\beta(0.3 \mathrm{U} / \mathrm{ml})$ h

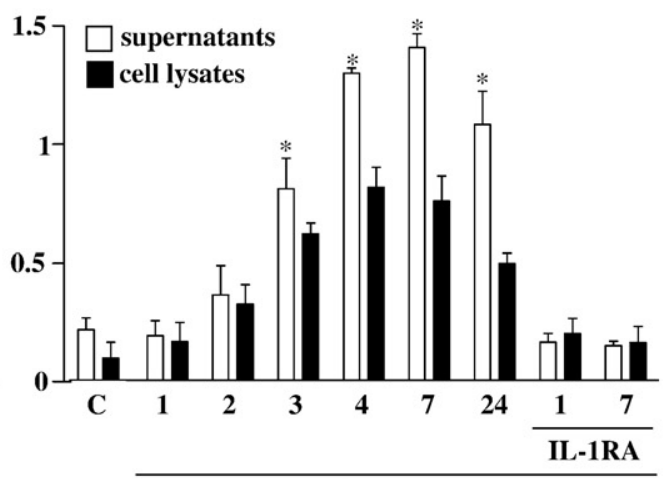

$\mathrm{IL}-1 \beta(0.3 \mathrm{U} / \mathrm{ml}) \mathrm{h}$

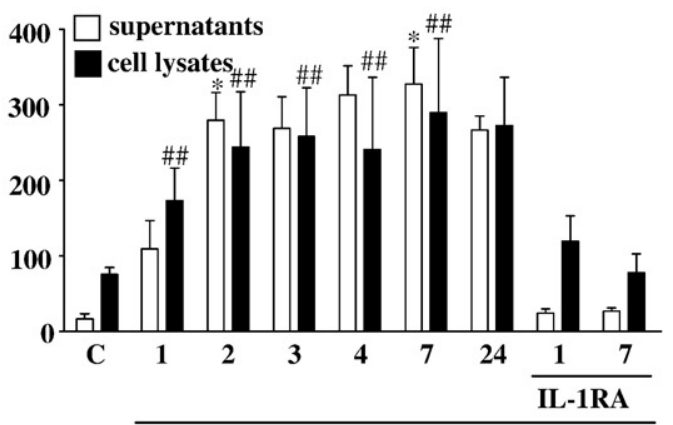

IL-1 $\beta(0.3 \mathrm{U} / \mathrm{ml})$ h

Fig. 3. Effect of IL- $1 \alpha$ and IL-1 $\beta$ on chemokine expression in primary cortical neurones. Cortical neurones were treated with vehicle (C) for $7 \mathrm{~h}$, IL-1 $\alpha$ or IL-1 $\beta$ $(0.3 \mathrm{U} / \mathrm{ml})$ for 1 to $24 \mathrm{~h}$. Cultures were also treated with IL-1 $\alpha$ or IL-1 $\beta$ in the presence or absence of IL-1RA $(50 \mathrm{ng} / \mathrm{ml})$ for 1 or $7 \mathrm{~h}$. Cell lysates and supernatants were assayed for KC (A), IP-10 (B) and MCP-1 (C) protein by ELISA. Data are presented as mean \pm SD of three independent experiments carried out on separate cultures. ${ }^{*} p<0.05,{ }^{* *} p<0.01, \mathrm{C}$ vs. IL-1 $\alpha$ or IL-1 $\beta$; ${ }^{\#} p<0.05,{ }^{\# \#} p<0.01$, IL-1 $\alpha$ vs. similar concentration of IL-1 $\beta$, using one-way ANOVA and Dunnett's multiple comparison post-hoc test.

al., 2008a). In order to understand whether the nSMase/Src kinase also governs the regulation of $\mathrm{KC}$, IP-10 and MCP-1 in neurones, we tested the effect of specific inhibitors of nSMase (3-OMS) and Src kinase (PP2) on IL-1-induced chemokine synthesis. We show that 3-OMS and PP2 did not induce significant reduction in the protein levels of the chemokines, whilst IL-6 levels in the same samples were significantly reduced (Tsakiri et al., 2008a). These results suggest that the regulation of chemokine synthesis by IL-1 in neurones occurs independently of nSMase/Src kinase signalling pathway activation.

In conclusion, we show that, in contrast to their differential effects on IL-6 synthesis, both IL-1 ligands induce strong synthesis and release of chemokines $\mathrm{KC}$, IP-10 and MCP-1, via an IL-1R1dependent and nSMase/Src kinase-independent mechanism, suggesting the existence of additional neuronal IL-1 signalling pathway(s).

Experimental methods

Animals

All studies were performed using cell cultures prepared from wild type mice (C57/BL6x129sv, Charles River, UK). Animal care and experimental procedures were conducted in accordance with the guidelines set by the 

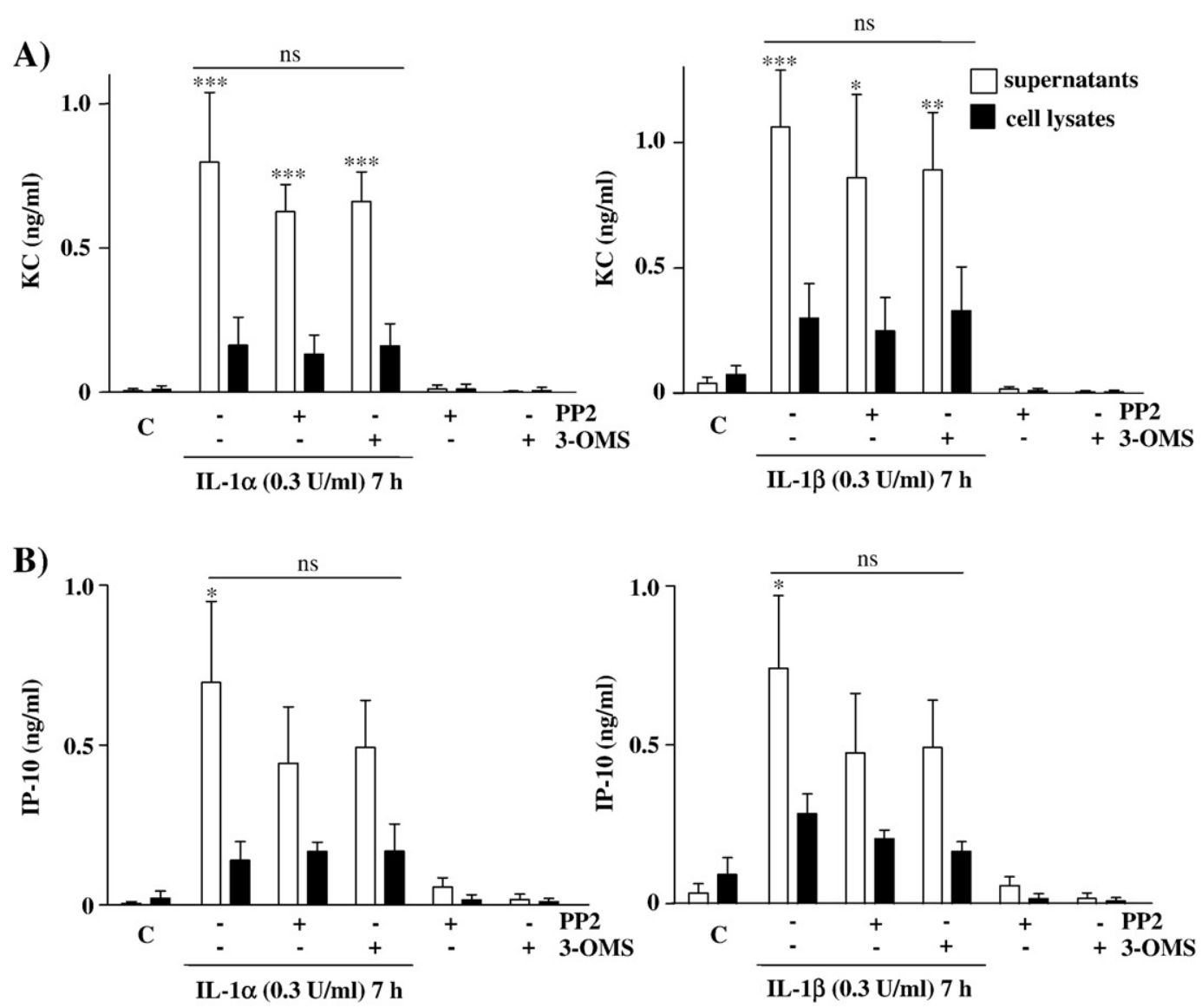

C)
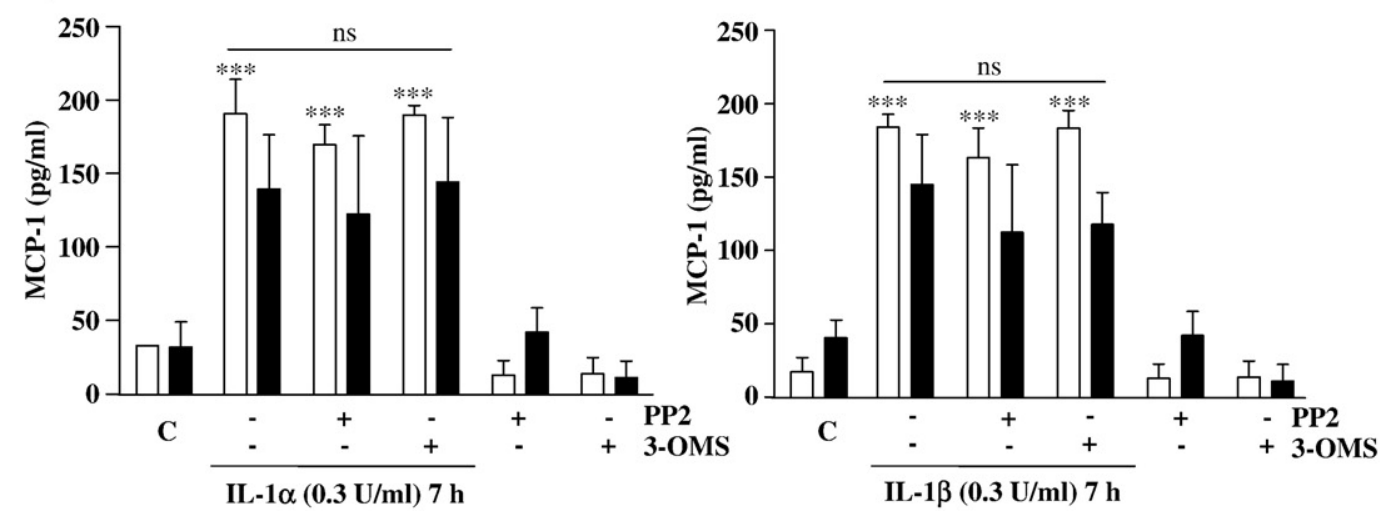

Fig. 4. Effect of Src kinase and nSMase inhibitors on IL-1 $\alpha$ - or IL-1 $\beta$-induced chemokines expression. Cortical neurones were treated with vehicle (C), IL-1 $\alpha$ or IL-1 $\beta(0.3 \mathrm{U} / \mathrm{ml})$ for $7 \mathrm{~h}$ in the absence or presence of the Src kinase inhibitor PP2 $(10 \mu \mathrm{M})$ or the nSMase inhibitor 3-OMS $(25 \mu \mathrm{M})$. As a control, neurones were also treated with 3-OMS or PP2 alone for $7 \mathrm{~h}$. Cell lysates and supernatants were assayed for KC (A), IP-10 (B) and MCP-1 (C) proteins by ELISA. Data are presented as mean $\pm \mathrm{SD}$ of three independent experiments carried out on separate cultures. ${ }^{*} p<0.05,{ }^{*} p<0.01,{ }^{* * *} p<0.001$, significant differences between control and treated groups, non-significant (ns) differences between IL-1 and IL-1+ PP2/3-OMS treatments, using one-way ANOVA with Bonferroni's multiple comparison post-hoc tests.

European Council directives (86/609/EEC) and the UK Home Office, Animals (Scientific Procedures) Act 1986.

\section{Reagents and drugs}

General laboratory reagents were obtained from Sigma (UK) or BDH Ltd (UK). Tissue culture reagents were supplied by Invitrogen (UK). Rat recombinant IL-1 $\alpha$, IL-1 $\beta$ and human recombinant IL-1 receptor antagonist
(IL-1RA) were provided by Dr. Steve Poole from the National Institute of Biological Standards and Controls (NIBSC, UK).

\section{Primary cortical neuronal cell culture and treatments}

Primary, neuronal cell cultures were prepared form embryonic (day 16) mice as described previously (Moore et al., 2002). The cultures were used on days 12-14. Cell-specific immunostaining revealed that all cultures 
were highly enriched of neurones with no glial contamination (data not shown).

For IL-6 mRNA expression, cultures were treated with rat recombinant IL- $1 \alpha$ or IL- $1 \beta(0.003,0.015,0.03,0.3,3$ or $30 \mathrm{U} / \mathrm{ml}$, diluted in vehicle $(0.1 \%$ low endotoxin bovine serum albumin (BSA) in sterile $0.9 \% \mathrm{NaCl}$ ) for $4 \mathrm{~h}$ (optimal time point of IL-6 mRNA expression) or $7 \mathrm{~h}$ (optimal time point for protein expression) (Tsakiri et al., 2008b). For cDNA micrroarray experiments, cultures were treated with vehicle or IL-1 $1 \beta(0.3 \mathrm{U} / \mathrm{ml})$, in the absence or presence of IL-1RA $(50 \mathrm{ng} / \mathrm{ml})$ for $4 \mathrm{~h}$. To assess the effect of IL-1 $\alpha$ and IL-1 $\beta$ on the synthesis of KC (CXCL1), IP-10 (CXCXL2) and MCP-1 (CCL2) proteins in neurones, primary cultures were treated with vehicle, IL-1 $\alpha$ or IL-1 $\beta(0.3 \mathrm{U} / \mathrm{ml})$ for 1 to $24 \mathrm{~h}$. Cultures were also treated with IL- $1 \alpha$ or IL- $1 \beta(0.3 \mathrm{U} / \mathrm{ml})$ for 1 or $7 \mathrm{~h}$ in the presence of IL-1RA $(50 \mathrm{ng} / \mathrm{ml})$. To investigate the involvement of Src kinase and nSMase on IL-1-induced chemokine expression, cultures were treated with vehicle, IL-1 $\alpha$ or IL-1 $\beta(0.3 \mathrm{U} / \mathrm{ml})$ in the absence or presence of the Src kinase inhibitor PP2 $(10 \mu \mathrm{M}$, Calbiochem, UK), or the nSMase inhibitor 3-O-methyl-sphingomyelin (3-OMS, $25 \mu \mathrm{M}$, Biomol, USA) for $7 \mathrm{~h}$.

\section{Real-time PCR}

Real-time PCR for IL-6 was performed as previously described (Tsakiri et al., 2008b) using specific oligonucleotide primers for IL-6 and $\beta$-actin (sequences available on request). For all experiments, control reactions using total RNA were performed to ensure that amplification was not a result of contamination with genomic DNA.

\section{cDNA microarray analysis}

Microarray analysis was performed with the GeneChip ${ }^{\circledR}$ Mouse Genome 430 2.0 Array (oligonucleotide arrays), which contains over 45,000 probe sets, representing well established mouse genes and unknown EST sequences. The sequences used for the probe design had been selected from the GeneBank ${ }^{\circledR}$, $\mathrm{dbEST}$ and RefSeq. The oligonucleotide probes had been synthesised in situ on the arrays, and eleven probes were used to measure the level of transcription of each sequence on the array. The arrays contained a set of mouse housekeeping genes that allowed the normalisation of the data. Biotin labelled cRNA samples were hybridised on the array platforms and stained with streptavidinphycoerythrin. The arrays were scanned in GeneChipScanner ${ }^{\circledR}$ and the results were analysed with the GeneChip Operating Software $\Re$. Data were normalised by global scaling, and data present in at least two of the three triplicate arrays were used for further analysis. The results were analysed with a parametric test that assumes equal variances, Benjamin and Hochberg False Discovery Rate multiple testing correction and Tukey's post-hoc test with a cut-off point of $p<0.05$, which produced a list of 152 genes.

\section{ELISA}

Immunoreactive IL-6, KC, IP-10 and MCP-1 in neuronal cell culture supernatants and cell lysates were assayed using a validated mouse-specific ELISAs (DuoSet) purchased from R\&D Systems (UK). Standards were assayed in triplicate and samples $(100 \mu \mathrm{l})$ in duplicate. The absorbance was then measured using a plate reader (MRX, Dynatech, UK), and results were calculated from the standard curve. The detection limits of the assays were $3 \mathrm{pg} / \mathrm{ml}$.

\section{Data analysis}

Data were analysed with GraphPad Prism 4.0 software, and expressed as the mean \pm standard deviation (SD) of at least three independent experiments carried out on separate cultures. Differences between treated and control groups were analysed by one-way analysis of variance (ANOVA) with Dunnett's multiple comparisons post-hoc test. Differences between IL-1 alone and IL-1 in the presence of inhibitors were analysed by one-way ANOVA with Bonferroni's post-hoc test. For all analyses, a value of $p<0.05$ was considered statistically significant.

\section{Acknowledgments}

This work was supported by the Medical Research Council and Syngenta. The authors would like to thank Dr Fei Ling Lim for his help with the cDNA microarray experiments, Dr Steve Poole from NIBSC for kindly providing rat recombinant IL-1 $\alpha$, IL-1 $\beta$ and human recombinant IL-1RA, and Dr Deborah Bentley for critically reviewing this manuscript.

\section{References}

Allan, S.M., Tyrrell, P.J., Rothwell, N.J., 2005. Interleukin-1 and neuronal injury. Nat. Rev., Immunol. 5, 629-640.

Andre, R., Pinteaux, E., Kimber, I., Rothwell, N.J., 2005. Differential actions of IL-1 alpha and IL-1 beta in glial cells share common IL-1 signalling pathways. NeuroReport 16, 153-157.

Anforth, H.R., Bluthe, R.M., Bristow, A., Hopkins, S., Lenczowski, M.J., Luheshi, G., Lundkvist, J., Michaud, B., Mistry, Y., Van Dam, A.M., Zhen, C., Dantzer, R., Poole, S., Rothwell, N.J., Tilders, F.J., Wollman, E.E., 1998. Biological activity and brain actions of recombinant rat interleukin-1alpha and interleukin-1beta. Eur. Cytokine Netw. 9, 279-288.

Barbero, S., Bajetto, A., Bonavia, R., Porcile, C., Piccioli, P., Pirani, P., Ravetti, J.L., Zona, G., Spaziante, R., Florio, T., Schettini, G., 2002. Expression of the chemokine receptor CXCR4 and its ligand stromal cell-derived factor 1 in human brain tumors and their involvement in glial proliferation in vitro. Ann. N.Y. Acad. Sci. 973, 60-69.

Bilbo, S.D., Biedenkapp, J.C., Der-Avakian, A., Watkins, L.R., Rudy, J.W., Maier, S.F., 2005. Neonatal infection-induced memory impairment after lipopolysaccharide in adulthood is prevented via caspase-1 inhibition. J. Neurosci. 25, 8000-8009.

Cho, C., Miller, R.J., 2002. Chemokine receptors and neural function. J. Neurovirology 8, 573-584.

Cumberbatch, M., Dearman, R.J., Groves, R.W., Antonopoulos, C., Kimber, I., 2002. Differential regulation of epidermal langerhans cell migration by interleukins (IL)-1alpha and IL-1 beta during irritant- and allergen-induced cutaneous immune responses. Toxicol. Appl. Pharmacol. 182, 126-135.

Dantzer, R., Bluthe, R.M., Gheusi, G., Cremona, S., Laye, S., Parnet, P., Kelley, K.W., 1998. Molecular basis of sickness behavior. Ann. N.Y. Acad. Sci. 856, 132-138.

Dower, S.K., Kronheim, S.R., Hopp, T.P., Cantrell, M., Deeley, M., Gillis, S., Henney, C.S., Urdal, D.L., 1986. The cell surface receptors for interleukin1 alpha and interleukin-1 beta are identical. Nature 324, 266-268.

Juric, D.M., Carman-Krzan, M., 2001. Interleukin-1 beta, but not IL-1 alpha, mediates nerve growth factor secretion from rat astrocytes via type I IL-1 receptor. Int. J. Dev. Neurosci. 19, 675-683.

Kim, M.O., Suh, H.S., Brosnan, C.F., Lee, S.C., 2004. Regulation of RANTES/CCL5 expression in human astrocytes by interleukin-1 and interferon-beta. J. Neurochem. 90, 297-308.

Moore, J.D., Rothwell, N.J., Gibson, R.M., 2002. Involvement of caspases and calpains in cerebrocortical neuronal cell death is stimulus-dependent. Br. J. Pharmacol. 135, 1069-1077.

Nakae, S., Asano, M., Horai, R., Iwakura, Y., 2001. Interleukin-1 beta, but not interleukin-1 alpha, is required for T-cell-dependent antibody production. Immunology 104, 402-409.

Parker, L.C., Luheshi, G.N., Rothwell, N.J., Pinteaux, E., 2002. IL-1beta signalling in glial cells in wildtype and IL-1RI deficient mice. Br. J. Pharmacol. 136, 312-320.

Ross, F.M., Allan, S.M., Rothwell, N.J., Verkhratsky, A., 2003. A dual role for interleukin-1 in LTP in mouse hippocampal slices. J. Neuroimmunol. 144, 61-67.

Rothwell, N., 2003. Interleukin-1 and neuronal injury: mechanisms, modification, and therapeutic potential. Brain Behav. Immun. 17, 152-157.

Schneider, H., Pitossi, F., Balschun, D., Wagner, A., del Rey, A., Besedovsky, H.O., 1998. A neuromodulatory role of interleukin-1beta in the hippocampus. Proc. Natl. Acad. Sci. U. S. A. 95, 7778-7783. 
Sims, J.E., March, C.J., Cosman, D., Widmer, M.B., MacDonald, H.R., McMahan, C.J., Grubin, C.E., Wignall, J.M., Jackson, J.L., Call, S.M., 1988. cDNA expression cloning of the IL-1 receptor, a member of the immunoglobulin superfamily. Science 241, 585-589.

Song, X., Voronov, E., Dvorkin, T., Fima, E., Cagnano, E., Benharroch, D., Shendler, Y., Bjorkdahl, O., Segal, S., Dinarello, C.A., Apte, R.N., 2003. Differential effects of IL-1 alpha and IL-1 beta on tumorigenicity patterns and invasiveness. J. Immunol. 171, 6448-6456.

Tsakiri, N., Kimber, I., Rothwell, N.J., Pinteaux, E., 2008a. Interleukin-1induced interleukin- 6 synthesis is mediated by the neutral sphingo-
myelinase/Src kinase pathway in neurones. Br. J. Pharmacol. 153, 775-783.

Tsakiri, N., Kimber, I., Rothwell, N.J., Pinteaux, E., 2008b. Mechanisms of interleukin-6 synthesis and release induced by interleukin-1 and cell depolarisation in neurones. Mol. Cell. Neurosci. 37, 110-118.

Wesche, H., Korherr, C., Kracht, M., Falk, W., Resch, K., Martin, M.U., 1997. The interleukin-1 receptor accessory protein (IL-1RAcP) is essential for IL-1-induced activation of interleukin-1 receptor-associated kinase (IRAK) and stress-activated protein kinases (SAP kinases). J. Biol. Chem. 272, 7727-7731. 